\title{
Alcohol Consumption as a Causator and/ or an Accelerator of Neuropathy in People With Diabetes Is Regularly Overlooked
}

\author{
David S. H. Bell (D) · Edison Goncalves (D)
}

Received: April 19, 2021 / Accepted: July 26, 2021 / Published online: August 19, 2021

(C) The Author(s) 2021

\begin{abstract}
Patients with diabetes and distal symmetrical polyneuropathy (DSP) are routinely evaluated for etiologies other than diabetes, including vitamin B12 deficiency, paraproteinemia, hypothyroidism and drug or autoimmune-induced neuropathy. However, the most common cause of DSP, next to that of diabetes, is alcohol intake, which is almost never evaluated. In addition to assessment of alcohol intake based on patient history, which often leads to an underestimation of alchohol intake, markers of a high alcohol intake (elevated liver enzymes, uric acid, triglycerides, low magnesium or low folic acid levels) should be obtained. However, the test that is most likely to detect surreptitious alcohol intake is urinary ethyl glucuronide (EtG), which will detect the intake of alcohol within the previous $90 \mathrm{~h}$. Detection of alcohol use is important since if alcohol consumption is not discontinued, DSP, whatever the etiology,
\end{abstract}

\section{S. H. Bell ( ()}

Southside Endocrinology, Southside Endocrinology, 1900 Crestwood Blvd, Suite 201, Irondale, AL 35210, USA

e-mail: dshbell@yahoo.com

E. Goncalves

Grandview Endocrinology, Grandview Medical

Group, 3525 Independence Dr, Homewood,

AL 35209, USA

e-mail: goncalves.edison@outlook.com will not improve. In addition, the use of drugs to improve symptoms of DSP (tricyclics, antiepileptics, serotonin, norepinephrine reuptake inhibitors and analgesics) may in combination with alcohol excessively suppress respiration and cognitive function such that these drugs should not be prescribed or utilized if use of alcohol continues. In the future, all patients with DSP, and especially those with symptomatic DSP, should be biochemically screened for excessive alcohol intake and appropriate action taken.

Keywords: Diabetic neuropathy; Alcoholic neuropathy; Ethyl Glucuronide

\section{Key Summary Points}

Neuropathy presenting in a person with diabetes may wholly or partially be due to other etiologies.

In patients with neuropathy, vitamin B12 deficiency, paraproteinemia and hypothyroidism should be eliminated.

Alcohol consumption may be a major etiological factor. 
Excessive alcohol consumption can be eliminated by examination of patient's medical history and testing for urinary ethyl glucuronide.

If excessive alcohol intake is a factor in the etiology of the neuropathy the treatment of the symptoms will only be treatable when alcohol intake stops.

Drugs used to treat the symptoms of neuropathy may in combination with alcohol cause cognitive dysfunction and suppress respiration.

This article is based on previously conducted studies and does not contain any new studies with human participants or animals performed by any of the authors.

The prevalence of distal symmetrical polyneuropathy (DSP) in an Italian population was found to be $3.5 \%$ in those over age 55 years, increasing to $5.3 \%$ in those over age 75 years [1]. In this study, $40 \%$ of those surveyed had diabetes, a prevalence similar to that reported in a Dutch population study which reported that diabetes was the cause of the DSP in 32\% of patients [2]. Other rarer and identifiable etiologies, such as vitamin B12 deficiency, hypothyroidism or paraproteinemia, can be eliminated with appropriate laboratory testing but, historically, testing for an alcohol etiology has not been utilized or recommended [3]. In the USA utilization of alcohol is the next most common cause of DSP after diabetes [4-6].

In most cases, alcohol intake can only be assessed from the patient history, which results, in most situations, in an underestimation of alcohol intake. Only when a very high alcohol intake is currently being utilized can excessive alcohol use be suspected through elevated levels of liver enzymes (serum glutamic oxaloacetic transaminase [SGOT] higher than serum glutamic pyruvic transaminase [SGPT]), triglycerides and uric acid or decreased levels of magnesium and folic acid. However, with a more moderate alcohol intake these tests will usually give normal results. Nowadays, assessment of ethyl glucuronide (EtG) levels in the urine can be utilized to assess the degree of alcohol intake in patients presenting with DSP, especially those who are suspected of having a high alcohol intake.

Pathologically, the effects of diabetes on the peripheral nerve are abnormalities of the sodium and calcium channels, altered neuropeptide expression, sympathetic sprouting, loss of spinal inhibitory control, altered blood flow and increased glycemic flux. Centrally increased thalamic vascularity, central sensitization and imbalances in facilitation/inhibition with the descending pathways add to the pathology [3].

Alcohol-induced neuropathy is thought to be due to activation of spinal cord microalga, oxidative stress, free radical damage, activation of mGlu5-receptors in the spinal cord as well as activation of the sympathoadrenal and hypothalamic-pituitary axes. In addition, nutritional deficiencies, particularly of thiamine, and/or the direct toxic effect of alcohol and its metabolites (particularly acetaldehyde) on the nerve may play a role [7]. Thus, there is very little, if any, overlap between the pathophysiologies of alcoholic and diabetic DSP, suggesting that peripheral nerve damage from these etiologies is likely to be additive [8]. An actual threshold of alcohol intake for the development of alcohol-induced neuropathy is unknown. However, the most important risk factor is lifetime alcohol dose, with neuropathy being more common with chronic rather than episodic alcoholism. Other risk factors are genetics, male gender and the type of alcohol consumed (higher for wine than for beer or spirits) [8].

While the etiologies and pathophysiologies of these conditions differ, the clinical findings are for all practical purposes indistinguishable. Both alcoholic and diabetic DSP present symptomatically with numbness, tingling, pain and early motor involvement of the toes. Neurological examination in both cases reveals decreased pinprick and/or vibration sense in a stocking distribution, decreased or absent ankle reflexes and weakness of toe extension. With both etiologies, when the sensory loss extends to knee level or above involvement of the upper limb occurs and throughout the process there are equal and progressive involvements of the autonomic nervous system. Therefore, differences between the effects of alcohol and 
diabetes on peripheral nerves cannot be differentiated clinically.

Over the years, we have regularly been misled by persons with diabetes who have symptoms and signs of DSP and who reported little or no alcohol intake. In one case, 20 years after the onset of neuropathy in a person with type 1 diabetes it was discovered that she had overutilized alcohol only when she presented with acute pancreatitis. In another case, a person with well-controlled type 2 diabetes had symptoms of DSP that were so severe that he required chronic narcotic therapy; alcohol abuse was only discovered when he requested an emergency visit to request a higher narcotic dose at which time it was noted that he smelt strongly of alcohol. His wife later stated that when he was first seen he had just been discharged from an alcohol rehabilitation program and truthfully stated that he did not use alcohol. Yet another was a retired healthcare provider whose diabetes was excellently controlled (HbA1c 6.1\%) on metformin monotherapy who presented with severe symptoms and signs of DSP. After his death we were informed by a relative that he was "a heavy drinker."

While symptoms but not signs of DSP may be controlled with improved glycemic control, if alcohol utilization is not discontinued and any thiamine deficiency corrected, there will be progression of nerve damage with accompanying progression of symptoms and signs of DSP.

Since we have regularly been misled by people with diabetes and symptoms and signs of DSP who reported little or no alcohol intake, and have come to the realization that we have been misled by these patients, we now rigorously search for a detailed history of alcohol consumption in people with diabetes and DSP and, if necessary confirm their history of alcohol intake with a urinary EtG level. EtG is a metabolite of alcohol formed by glucuronidation. It is detectable in the urine for up to $90 \mathrm{~h}$ after alcohol intake, and for longer periods in a hair sample, after the utilization of alcohol has ceased and alcohol itself is no longer detectable in the serum [9-11].

An additional concern is that the use of medications to improve the symptoms of neuropathy (tricyclics, anti-epileptics, serotonin and norepinephrine reuptake inhibitors and analgesics) may in combination with alcohol suppress respiration so that unless alcohol use ceases these drugs should be withheld or withdrawn. In addition, whatever the etiology there will be no clinical improvement in the DSP if alcohol use is not discontinued.

In conclusion, previously when faced with a person with diabetes and DSP we have assumed that the sole etiology of the DSP is diabetes unless there is evidence of vitamin B12 deficiency, paraproteinemia or hypothyroidism. Since overall in the USA only $40 \%$ of DSP is due to diabetes we should in these patients be considering the second most common cause of DSP, i.e. a chronic and heavy intake of alcohol. In addition, in seeking an accurate historical assessment of alcohol intake we may need to perform a urinary EtG test because if the consumption of alcohol is not discontinued then the DSP both subjectively and objectively will not improve and will most likely worsen whether the etiology of the DSP is primarily diabetes, alcohol abuse or diabetes plus alcohol abuse. Therefore, in the future all persons with diabetes presenting with DSP, and especially painful DSP, should be rigorously screened for alcohol intake. Questioning people with diabetes and DSP about their alcohol intake is not sufficient; biochemical testing should be performed in all subjects and therapy should be withheld until alcohol as a cause of DSP has been ruled out.

Future research should concentrate on the pathophysiology of the combination of alcohol and diabetes in damaging neurons. The development of medications that would specifically treat these pathophysiologies should be developed so that more than symptomatic therapies are available to the person with diabetes and DSP caused by diabetes and/or alcohol.

\section{ACKNOWLEDGEMENTS}

Funding. No funding or sponsorship was received for this study or publication of this 
article. The Rapid Service Fee is complementary to Editorial Board member.

Authorship. All named authors meet the International Committee of Medical Journal Editors (ICMJE) criteria for authorship for this article, take responsibility for the integrity of the work as a whole, and have given their approval for this version to be published.

Authorship Contributions. Authors contributed equally to the manuscript in all areas.

Disclosures. David S.H. Bell: Amarin, Esperion. Edison Goncalves: Novo-Nordisk.

Compliance with Ethics Guidelines. This article is based on previously conducted studies and does not contain any new studies with human participants or animals performed by any of the authors.

Open Access. This article is licensed under a Creative Commons Attribution-NonCommercial 4.0 International License, which permits any non-commercial use, sharing, adaptation, distribution and reproduction in any medium or format, as long as you give appropriate credit to the original author(s) and the source, provide a link to the Creative Commons licence, and indicate if changes were made. The images or other third party material in this article are included in the article's Creative Commons licence, unless indicated otherwise in a credit line to the material. If material is not included in the article's Creative Commons licence and your intended use is not permitted by statutory regulation or exceeds the permitted use, you will need to obtain permission directly from the copyright holder. To view a copy of this licence, visit http://creativecommons.org/licenses/by$\mathrm{nc} / 4.0 /$.

\section{REFERENCES}

1. [No authors listed]. Chronic symmetric symptomatic polyneuropathy in the elderly: a field screening investigation in two italian regions. I. Prevalence and general characteristics of the sample. Italian General Practitioner Study Group (IGPSG). Neurology. 1995;45(10):1832-6.

2. Visser NA, Notermans NC, Linssen RS, van den Berg $\mathrm{LH}$, Vrancken AF. Incidence of polyneuropathy in Utrecht, the Netherlands. Neurology. 2015;84(3): 259-64.

3. Tesfaye S, Boulton AJM, Dickenson AH. Mechanisms and management of diabetic painful distal symmetrical polyneuropathy. Diabetes Care. 2013;36(9):2456-65.

4. Callaghan BC, Price RS, Feldman EL. Distal symmetric polyneuropathy: a review. JAMA. 2015;314(20):2172-81.

5. Lubec D, Müllbacher W, Finsterer J, Mamoli B. Diagnostic work-up in peripheral neuropathy: an analysis of 171 cases. Postgrad Med J. 1999;75(890): 723-7.

6. England JD, Gronseth GS, Franklin G, et al. Practice parameter: evaluation of distal symmetric polyneuropathy: role of laboratory and genetic testing (an evidence-based review). Report of the American Academy of Neurology, American Association of Neuromuscular and Electrodiagnostic Medicine, and American Academy of Physical Medicine and Rehabilitation. Neurology. 2009;72(2):185-92.

7. Chopra K, Tiwari V. Alcoholic neuropathy: possible mechanisms and future treatment possibilities. Br J Clin Pharmacol. 2012;73(3):348-62.

8. Julian T, Glascow N, Syeed R, Zis P. Alcohol-related peripheral neuropathy: a systematic review and meta-analysis. J Neurol. 2019;266(12):2907-19.

9. Walsham NE, Sherwood RA. Ethyl glucuronide. Ann Clin Biochem. 2012;49(Pt 2):110-7.

10. Biondi A, Freni F, Carelli C, Moretti M, Morini L. Ethyl glucuronide hair testing: a review. Forensic Sci Int. 2019;300:106-19.

11. Kharbouche H, Sporkert F, Staub C, Mangin P, Augsburger M. Ethyl glucuronide: a biomarker of alcohol consumption. Praxis (Bern 1994). 2009;98(22):1299-306. 